\title{
GESTÃo PÚBLICA E CIDADANIA: METODOLOGIAS PARTICIPATIVAS EM AÇÃO
}

Fernando Guilherme Tenório

Jacob Eduardo Rozenberg 


\section{Os Autores}

\section{Fernando Guilherme Tenório}

Professor Adjunto e Coordenador do Programa de Estudos em Gestão Social (PEGS) da Escola Brasileira de Administração Pública (EBAP), da Fundação Getúlio Vargas (FGV).

\section{Jacob Eduardo Rozenberg}

Mestre em Administração Pública (FGV/EBAP). 


\section{ÍNDICE}

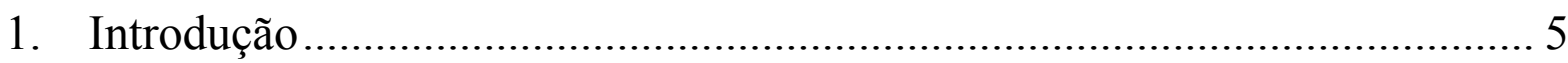

2 Participação, cidadania e outros conceitos ................................................... 6

3. A pesquisa: proposta e características da amostra ….................................. 9

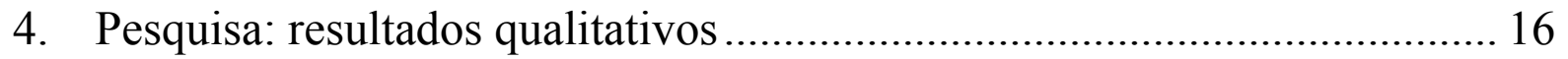

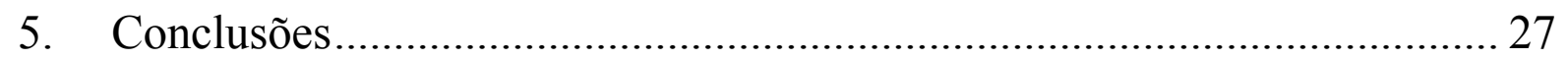




\section{Introdução}

A magnitude dos problemas sociais brasileiros, com todas as suas nuanças e complexidades, é um tema que desafia a capacidade de resolução da administração pública. A intensificação do processo de desvalorização social impõe à administração pública a adoção conjunta de soluções emergenciais atenuantes dos seus efeitos perversos e de soluções sólidas e duradouras comprometidas com a transformação definitiva de um quadro marcado pela crescente pauperização e agravamento da exclusão social.

Durante décadas a intervenção governamental sobre um quadro de grave desbalanceamento social foi desperdiçada em ações paliativas, de forte cunho assistencialista, que atuavam na própria retroalimentação da miséria e manutenção do status quo, pouco contribuindo para transformações efetivas no sentido da conquista da cidadania e de condições mais dignas de existência. Este panorama, contudo, vem se modificando de forma lenta mas gradual a partir do próprio processo de consolidação da democracia no país nos anos 80. Por um lado, vemos o Estado reconhecer sua incapacidade de assumir a responsabilidade exclusiva e isolada pela formulação de políticas públicas e pela tomada de decisões sobre temas e questões que, na verdade, pertencem ao conjunto da sociedade. Por outro, a sociedade busca encontrar o seu espaço de influência através do desenvolvimento de formas variadas de organização social, da abertura de novos canais de participação, do incremento na interação com o âmbito governamental e da assimilação de instrumentos e técnicas de gestão social que tornem suas ações mais eficientes e eficazes. A parceria entre Estado e sociedade parece cada vez ganhar mais adeptos em torno da busca de soluções para remover os obstáculos colocados diante da sociedade na luta pela conquista da cidadania plena.

Contudo, antes que a participação popular e a parceria Estado-sociedade sejam encaradas como solução universal para todos os problemas sociais, é indispensável promover a separação entre o joio e o trigo. Em outras palavras, é necessário evitar a homogeneização e vulgarização dessas experiências, procurando distinguir a legítima participação da mera manipulação, formas válidas de cooperação Estado-sociedade da simples cooptação ou, o que é mais grave, da pseudo-participação.

Tendo em vista a multiplicidade de experiências colocadas em prática que assinalam a presença da participação e do entrosamento entre Estado e sociedade enquanto traços marcantes de seu modus operandi, este estudo teve como objetivo analisar um conjunto 
destas iniciativas buscando identificar quais as características que as aproximavam metodologicamente. Com isso, pretendeu-se verificar o que se pode esperar em termos de estímulo à participação consciente e legítima da sociedade e de contribuição para a formação e capacitação dos atores sociais e para o estabelecimento de uma relação Estadosociedade onde a cidadania seja de fato uma construção e um exercício permanente.

Os programas e projetos aqui examinados compõem o grupo de 100 (cem) experiências escolhidas como semifinalistas do Programa Gestão Pública e Cidadania, iniciativa conjunta da Fundação Getulio Vargas e da Fundação Ford com vistas a premiar experiências inovadoras na área de administração pública. Estas experiências foram selecionadas entre 629 (seiscentas e vinte e nove) iniciativas inscritas em 1996, primeiro ano de existência do programa no Brasil. O grande número de projetos participantes por si só sinaliza positivamente no sentido de que novas perspectivas de soluções para as questões sociais estão sendo buscadas. Por outro lado, serve ainda como justificativa para a realização desta pesquisa por ressaltar a necessidade de se aprofundar a análise do comportamento das experiências ditas participativas.

Antes de descrever as características metodológicas das experiências destacadas, revisaremos o significado de conceitos como cidadania e participação que, por serem amplamente difundidos e utilizados, muitas vezes têm o seu sentido distorcido ou mal compreendido. Somente então, será possível empreender a averiguação dos chamados projetos inovadores e apontar características metodológicas afins.

\section{Participação, cidadania e outros conceitos}

A participação integra o cotidiano de todos os indivíduos. Ao longo da vida e em diversas ocasiões somos levados, por desejo próprio ou não, a participar de grupos e atividades. O ato de participar, tomar parte, revela a necessidade que os indivíduos têm em se associar na busca de alcançar objetivos que lhes seriam de difícil consecução ou até mesmo inatingíveis caso fossem perseguidos individualmente, de maneira isolada.

A participação social e a cidadania referem-se à apropriação pelos indivíduos do direito de construção democrática do seu próprio destino. Sua concretização passa pela organização coletiva dos participantes, possibilitando desde a abertura de espaços de discussão dentro e fora dos limites da comunidade até a definição de prioridades, elaboração de estratégias de ação e estabelecimento de canais de diálogo com o poder público. 
Porém, a interrogação que paira sobre as experiências que envolvem a participação está relacionada com o grau de domínio e de compreensão dos participantes sobre o processo em que estão inseridos. A participação que se espera depende, portanto, da reunião de atributos que serão agora examinados.

Em primeiro lugar, participação requer consciência sobre os seus atos. Logo, participação consciente é aquela em que os envolvidos possuem a compreensão sobre o processo que estão vivenciando. Quando uma pessoa ou grupo de pessoas agem sem o entendimento das razões e conseqüências de seus atos, a participação é restrita, estabelecida em função de alguma espécie de relação de dominação, onde, a partir de algum tipo de poder persuasivo, determinado grupo impõe aos demais as decisões e os passos que devem ser seguidos. Nestas situações, a falta de senso crítico faz a participação pouco se distinguir do simples adestramento. Dentre as formas de dominação, a mais sutil e por isso mesmo mais perversa é a que mantém as pessoas alijadas do acesso à informação e à educação, instrumentos fundamentais para a equalização das oportunidades e eliminação de injustiças.

Somente a participação consciente possibilita o reconhecimento das relações de interesse e poder que, ocultas ou manifestas, tentam se desenrolar associadas ao processo participativo. A compreensão das motivações que inspiram o comportamento de pessoas ou grupos é de extrema relevância para inibir o desvirtuamento do ímpeto participativo, evitando a sua transformação em mobilização popular manobrada e desviada na direção de interesses egoístas.

Uma segunda característica da participação está na forma de assegurá-la. Como bem expressou Demo", "não há participação imposta, concedida ou doada". Logo, a participação não pode ser forçada nem aceita como donativo. Sua legitimidade encontra-se na conscientização da sua importância, da negociação de espaços para o seu exercício e do estabelecimento das regras que irão democraticamente delimitar a sua prática. A ampliação e o aperfeiçoamento dos mecanismos e dos espaços participativos demandam tempo e uma ação continuada.

Um outro aspecto ratifica o valor da participação conquistada. Quando a participação é concedida, sem que qualquer empenho tenha sido feito nesta direção, dificilmente verificase um processo de internalização e de absorção deste direito por parte dos beneficiários. A

${ }^{1}$ Demo, Pedro. Participação e Planejamento - Arranjo Preliminar. Revista de Administração Pública. Rio de Janeiro, FGV, 25 (3): jul/set. 1991. 
tendência, a menos que uma ação educativa e conscientizadora tenha lugar, é o seu esvaziamento ou, o que é pior, a sua apropriação por parte de alguns poucos que passam a fazer política pessoal e manipular o poder em nome da coletividade. Nestas condições, da mesma forma como foi concedida, a participação pode ser retirada. Por outro lado, quando a participação é resultante de organização e mobilização sociais, sua prática tende a ser menos suscetível a ações que invistam a favor de seu enfraquecimento e cerceamento.

A voluntariedade da participação é outro aspecto que contribui para a sua legitimidade. Seria contraditório reivindicar a obrigatoriedade para um processo que se deseja consciente e gerador de um indivíduo mais comprometido com mudanças. O envolvimento direto e sem a intermediação por terceiros do indivíduo com os seus problemas e com a busca de soluções não pode se dar por imposição ou qualquer tipo de coação. A falta de uma cultura de participação e a realidade marcada pela luta diária pela sobrevivência atuam, muitas vezes, como agentes refreadores do engajamento popular na vida comunitária. Por outro lado, a mobilização social depende de se acreditar que soluções possam nascer do envolvimento da própria comunidade organizada, a partir da criatividade, do companheirismo e do inconformismo com certa realidade que se quer transformar.

A participação, portanto, deve ser vista como o grande instrumento de acesso à cidadania. Em sua plenitude, a cidadania só se consolida na presença de uma participação entendida enquanto ação coletiva e exercício consciente, voluntário e conquistado. Contudo, apesar de condição sine qua non para a construção da cidadania, a participação não se constitui no seu único e exclusivo requisito. Para o alcance da cidadania plena, a organização social e a participação política deverão vir associadas à superação das desigualdades econômicas. "Nenhuma solução social é relevante e profunda se não passar pela questão produtiva, bem como se não passar pela questão política"2. Segundo Demo, a transposição dos entraves decorrentes das duas faces da pobreza, a política e a econômica, é esforço que conjuga duas ações ${ }^{3}$ :

“-de um lado, capacidade de produzir/trabalhar, para superar a dependência material; de outro, capacidade de se organizar politicamente, para superar a dependência política.”

\footnotetext{
${ }^{2}$ Demo, Pedro. Op. Cit., p. 34

${ }^{3}$ Ibid., p. 33
} 
Partindo-se do pressuposto de que o duplo desafio acima referido está longe de ser uma realidade para parcela considerável da população, está-se diante de uma cidadania incompleta que pode ser também denominada de cidadania passiva ou inerte, aonde o cidadão é visto apenas nas suas atribuições enquanto eleitor, contribuinte e cumpridor das leis. A esta concepção restrita de cidadania contrapõe-se a de cidadania ativa, ou seja, "aquela que institui o cidadão como portador de direitos e deveres, mas essencialmente, criador de direitos para abrir novos espaços de participação política. ${ }^{4}$

A utilização corrente e já popularizada da expressão "resgate da cidadania" implica grave erro conceitual e merece ser revista. A ação de resgatar subentende a recuperação de algo que já pertenceu e que foi perdido e este, sem dúvida alguma, não é o caso da cidadania no Brasil. Muito pelo contrário, a cidadania no país está em processo de construção e, desta forma, deve ser encarada como uma conquista dos que tomam parte no processo.

Os projetos que serão aqui tratados constituem-se em experiências que, de diversas formas, tentam fomentar, na prática, a introdução de processos participativos que concorram para a formação da chamada cidadania ativa.

\section{A pesquisa: proposta e características da amostra}

\subsection{Proposta da pesquisa}

A quantidade e a qualidade das informações reunidas pelo Programa Gestão Pública e Cidadania proporcionam amplo conteúdo para a elaboração de estudos centrados na capacidade da administração pública prover soluções criativas e inovadoras para problemas locais. Esta pesquisa constituiu-se, assim, num dos resultados que começam a ser gerados pelo Programa, estando apoiada no material coletado e colocado à disposição da comunidade acadêmica para a realização de estudos subsidiários e complementares que venham a aprofundar os conhecimentos e a focalizar novos ângulos e perspectivas de ação no âmbito local.

Esta pesquisa não teve a intenção de tratar pontos específicos das experiências que perfazem a amostra, ou seja, as 100 iniciativas classificadas como semifinalistas do Programa. Ao contrário, a proposta foi a de não trabalhar com as particularidades, mas sim centrar-se nas afinidades, isto é, verificar quais os traços metodológicos que

${ }^{4}$ Benevides, Maria Vitória. Demnocracia e Cidadania. Participação popular nos governos locais. In: Publicações POLIS. São Paulo: POLIS, 1994, p. 16. 
predominavam e quais as características mais marcantes entre experiências que englobam temas, públicos-alvo e áreas de localização diversos, quanto ao envolvimento da cidadania.

\subsection{A seleção das experiências}

De acordo com o regulamento estabelecido pela Fundação Ford e Fundação Getulio Vargas, estariam aptos a participar do Programa Gestão Pública e Cidadania os projetos, programas ou atividades de administração pública com pelo menos um ano de operação efetiva, desenvolvidas por instituições públicas governamentais dos níveis estadual e municipal, e por organizações próprias dos povos indígenas. As experiências deveriam promover algum tipo de inovação em estratégias técnicas ou administrativas e contribuir para o aumento da capacidade de atendimento das demandas sociais e comunitárias. Ao longo do processo de seleção que resultou na escolha dos semifinalistas e, posteriormente, na definição das 20 experiências premiadas, foram levados em consideração os seguintes aspectos:

- representar uma mudança substancial, qualitativa ou quantitativa, com relação a práticas e estratégias anteriores em determinada área geográfica ou temática, seja através da implantação de um novo programa ou conjunto de atividades, seja por intermédio de um significativo aprimoramento de atividades ou programas existentes;

- apontar caminhos pelos quais a experiência poderia ser repetida por (ou transferida para) outras regiões ou instituições;

- ampliar ou consolidar formas de acesso da sociedade a seus agentes públicos, elevando a qualidade das práticas políticas institucionais;

- utilizar recursos locais ou oportunidades, nacionais e internacionais, na perspectiva de desenvolvimento responsável, estimulando, sempre que possível, práticas nativas e autônomas, que possam tornar-se auto-sustentáveis.

A partir da inscrição inicial dos 629 projetos teve lugar a primeira etapa seletiva. Um comitê técnico composto por membros de entidades acadêmicas e da sociedade civil esteve incumbido desta responsabilidade que resultou na definição das 100 iniciativas semifinalistas que agora compõem a amostra desta pesquisa. No Anexo I, é apresentada a lista das experiências e sua localização geográfica.

\subsection{As características da amostra}

A diversidade é, sem dúvida alguma, a palavra que melhor define o conjunto das experiências analisadas. Desde o ponto de vista geográfico, com iniciativas que atravessam o país de norte a sul, passando pela variedade de segmentos sociais 
participantes e pela multiplicidade de questões abordadas, abre-se um leque extraordinário de ações envolvendo a administração pública que, em comum, objetiva trazer soluções criativas e inovadoras para algum problema de natureza local. Serão agora apresentadas algumas características da amostra baseadas nas informações requisitadas aos responsáveis pelos programas e projetos classificados como semifinalistas. Faz-se necessário ressaltar que cinco destas experiências não procederam ao retomo destas informações, fato que de forma alguma invalida ou prejudica as conclusões que serão extraídas desta pesquisa. Exemplos concretos serão apresentados de maneira a enriquecer o texto e a sustentar as afirmações feitas.

Num primeiro momento serão examinadas algumas características da amostra, tais como a sua classificação por áreas e subáreas temáticas, a sua distribuição geográfica, a população-alvo atendida e o tempo de existência dos projetos. Em seguida, serão feitas considerações sobre as metodologias empregadas nas experiências.

\subsubsection{Distribuição por Áreas e Subáreas}

Uma primeira característica da amostra refere-se à variedade dos temas enfocados. À guisa de classificação, os programas e projetos que configuram a amostra podem ser desmembrados em diversas áreas e subáreas como apresentado no Anexo II.

\subsubsection{Distribuição geográfica e amplitude espacial das experiências}

Com relação à distribuição geográfica, constata-se a presença de projetos provenientes de todas as regiões do país, estando o maior volume de experiências concentrado na região Sudeste, com mais da metade do total (Tab. 1). O Estado de São Paulo, com 25 projetos, foi aquele que mais se fez representar, seguido de Minas Gerais, Paraná e Rio Grande do Sul com respectivamente 19, 9 e 7 iniciativas participantes. 
Tabela 1 - Distribuição das Experiências por Regiões

\begin{tabular}{|c|c|}
\hline Região & $\mathbf{N}^{\mathbf{0}}$ de projetos \\
\hline Norte & 6 \\
\hline Sul & 19 \\
\hline Centro-Oeste & 8 \\
\hline Nordeste & 14 \\
\hline Sudeste & 53 \\
\hline Total & $\mathbf{1 0 0}$ \\
\hline
\end{tabular}

Outro aspecto que merece ser focalizado é o que trata da amplitude das experiências. O regulamento do Programa Gestão Pública e Cidadania concede o direito de participação a iniciativas com dimensões variadas, abrangendo desde programas estaduais e regionais até projetos cujo campo de ação restringe-se ao espaço micro, ou seja, ao atendimento de uma comunidade específica, de uma favela, de uma reserva indígena. De fato, o que se verifica na amostra é a coexistência entre experiências de dimensões tão díspares como, por exemplo, o Programa Pobreza e Meio Ambiente na Amazônia - POEMA, que contempla vários estados da Região Norte, e o Projeto Castelinho, em Fortaleza, cujo objetivo básico é o de beneficiar 50 famílias moradoras em uma área de ocupação. Entre um pólo e outro o espaço municipal constitui-se em locus privilegiado da concretização de experiências públicas. O poder local emerge deste Programa na condição de fonte de propostas de soluções para questões que de tão especificas e localizada, fogem à percepção do nível de governo macro ou federal, só podendo ser enfrentadas a partir de um olhar microdirecionado.

\subsubsection{Público-alvo}

Quanto ao público-alvo as experiências podem ser classificadas em três categorias: aquelas que atingem a totalidade da população local, as que buscam a satisfação das demandas de um público específico e as mistas, ou seja, as que executam ao mesmo tempo ações mais gerais e ações que incidem sobre alguma clientela específica.

No primeiro grupo, ou seja, o das experiências em que não há seleção de beneficiários, mas sim uma generalização dos benefícios a toda a população, estão enquadrados em torno de $25 \%$ dos projetos da amostra. A título de ilustração, três exemplos são apresentados: 
a) Porto Alegre Mais - Cidade Constituinte, que possibilita a toda a população de Porto Alegre, individualmente ou via representantes de entidades, discutir os rumos da gestão da cidade e participar da formulação das diretrizes e propostas que, após debatidas e sistematizadas, são encaminhadas à Câmara Municipal na forma de Projeto de Lei.

b) O Projeto de Criação e Implantação de Postos e Serviços de Atendimento ao Cidadão -SAC, em Salvador (BA), que, através da concentração num mesmo espaço físico de uma série de serviços públicos de todas as esferas governamentais, objetiva facilitar o acesso do cidadão aos serviços, melhorar o atendimento e reduzir os custos.

c) O Programa de Humanização do Trânsito, em Novo Hamburgo (RS), em que toda a população da cidade é merecedora da atenção do programa que, através da educação e da mudança de atitudes com relação ao trânsito, tenciona reduzir e até mesmo eliminar a ocorrência de acidentes de trânsito. O programa conta com a participação direta da comunidade e com a colaboração de instituições tais como agremiações estudantis, sindicatos, imprensa, Polícias Civil e Militar, entre outros.

De natureza inversa aos exemplos supracitados, a maioria dos programas e projetos analisados nesta pesquisa foi implantada para beneficiar estratos específicos da população. Relevante, sem dúvida, é verificar a constelação de distintos públicos atendida pela amostra. São, quase todos, grupos imersos em situações de exclusão, padecendo das conseqüências de estigmas sociais e culturais há muito enraizados na sociedade. Numa primeira categorização estaria enquadrada a população de baixa renda residente em favelas, na periferia das cidades, em áreas de risco e na zona rural. Diversas iniciativas foram colocadas em prática com o intuito de trazer melhorias na qualidade de vida desta população sendo que foram muitos os projetos preocupados com a geração de emprego e renda para os pequenos produtores rurais e urbanos, desempregados e subempregados. Outra parcela de iniciativas teve como destinatário final grupos sociais marginalizados e minorias, entre os quais: crianças, mulheres, idosos, deficientes e índios. São citados alguns exemplos de ações voltadas para estes grupos: 
a) O Programa Nutrir, em Apucarana (PR), desenvolvido para beneficiar crianças em idade escolar, gestantes e desnutridos de $\mathrm{O}$ a 6 anos, através do fornecimento de alimentação de origem alternativa e de medicamentos fitoterápicos, entre outras medidas.

b) O Projeto Conviver, em Duque Bacelar (MA), que busca reintegrar os idosos na vida social por intermédio de oficina, dando-lhes a oportunidade de transferir aos mais jovens os seus conhecimentos acumulados. Além de se sentir útil, o idoso atua no fortalecimento e na preservação do saber da cultura popular.

c) Os Centros de Convivência, localizados em Belo Horizonte (MG), garantem aos usuários dos serviços de saúde mental espaços de criação, expressão e produção em oficinas de arte e artesanato, apostando neste caminho como meio de romper com preconceitos e estimular as relações sociais.

Finalmente, um conjunto distinto de projetos voltaram-se para o atendimento de um outro tipo de beneficiários: o próprio setor público. São iniciativas que, de alguma forma, tentam promover um salto de qualidade em alguma área ou setor da administração pública e que direta ou indiretamente, repercutirá na própria sociedade. Alguns exemplos deste tipo de intervenção são citados.

a) A Administração Estratégica, em Vitória (ES), que tem entre seus métodos de gestão o Programa de Qualidade que visa à melhoria da qualidade da prestação dos serviços públicos municipais.

b) O Sistema de Acompanhamento da Prefeitura, em Angra dos Reis (RJ), cujo público-alvo é composto por diversos órgãos públicos e os representantes no Conselho de Orçamento Participativo, que passarão a contar com maior transparência e detalhamento nas informações sobre as despesas da Prefeitura.

c) Núcleo de Informação em Mortalidade - NIM, em Londrina (PR), que passa a ser um importante instrumento de informação e de balizamento no planejamento de ações na área de saúde pelos profissionais de saúde municipais, beneficiários primários da experiência.

d) Curso de Administração Municipal de Araraquara (SP), tendo como público-alvo os funcionários públicos municipais. Entre seus objetivos, 
destacam-se a capacitação do servidor público e a criação de um espaço de conhecimento sobre a esfera municipal.

É interessante registrar, também, a existência de algumas experiências que poderíamos chamar de mistas, isto é, por um lado abrangem uma população ampla, e por outro desenvolvem ações específicas para determinado grupo. Esta categoria é composta por um número mais limitado de experiências. Citamos alguns exemplos:

a) O Modelo de Gestão dos Resíduos Sólidos, em Belo Horizonte (MG), compreendendo uma iniciativa que visa criar, através da comunicação e da mobilização social, uma nova consciência em toda a população do município com relação à questão do lixo e da limpeza urbana. Concomitantemente, são desenvolvidos trabalhos específicos com catadores de papel e moradores de vilas e favelas, na geração de emprego e renda.

b) A Unidade Experimental de Compostagem e Reciclagem, em Brazlândia (DF), que tem toda a população como beneficiária do projeto, buscando dar um tratamento adequado e racional ao lixo urbano. Por sua vez, os catadores de lixo que atuavam no lixão local estão sendo atendidos a partir de um processo que engloba a sua organização coletiva e abrange a coleta seletiva, o tratamento do lixo, a comercialização de recicláveis e a produção de adubo orgânico.

Com relação ao percentual da clientela potencial atendida pelos projetos, a seguinte apreciação pode ser feita. Inicialmente, é necessário assinalar que, para uma parcela substancial das experiências, as suas próprias características impossibilitam ou dificultam a aferição numérica da população beneficiada. São projetos em que a população participa através de representantes ou em que os benefícios não são tangíveis como, por exemplo, a disseminação de informações e a mudança de hábitos. Da mesma forma, nem sempre e factível precisar o montante total da população-alvo para verificar à eficácia da experiência.

Nos casos em que se encontram explicitados os percentuais da demanda beneficiada, observa-se que os projetos situam-se em estágios variados. Os percentuais variam entre $1 \%$ e $100 \%$ do público-alvo potencial já atingido. É 
difícil definir causas gerais que expliquem esta grande amplitude registrada. Cada projeto apresenta seu próprio ritmo, muitas vezes contando com metas de curto, médio e longo prazos, defrontando-se com situações específicas que atuam enquanto freios ou aceleradores do processo.

\subsubsection{Tempo de existência dos projetos}

Uma característica marcante dos projetos é o fato de serem, na sua maioria, experiências relativamente recentes. Menos de $20 \%$ dos projetos que compõem a amostra surgiram ainda na década de 80 . Inversamente, mais de $60 \%$ das iniciativas têm menos de três anos de existência, o que, em se tratando de projetos sociais, é certamente um período muito curto para se avaliar com plenitude as conseqüências sobre os beneficiários e os impactos, previstos ou não, sobre a ambiência e a população como um todo.

A curta duração das experiências e, portanto, a falta de tempo hábil para consolidar efetivamente suas propostas e metodologias tornam os projetos mais vulneráveis a pressões e situações de dificuldade que operam a favor da sua descontinuidade. Projetos na área social, sobretudo os de natureza participativa, necessitam de um período de maturação para serem assimilados e ganhar dinamismo. Não foi sem razão que a descontinuidade administrativa, mal típico do setor público, foi apontada como um dos principais riscos a que estão sujeitas essas iniciativas.

\section{Pesquisa: resultados qualitativos}

Feita a descrição de algumas características da amostra, passaremos a examinar aspectos concernentes à metodologia dos programas e projetos. Em especial, estávamos interessados em aprofundar a compreensão sobre dois tópicos específicos: em primeiro lugar, identificar de que forma as experiências inovadoras incorporaram a participação social. Em segundo lugar, estávamos interessados em analisar as possibilidades de relacionamento entre Estado e sociedade que afloram a partir destas iniciativas.

A pesquisa foi muito mais de natureza qualitativa do que quantitativa. Seria simplista buscar respostas com extremo rigor para questões imersas em um contexto marcado pelo dinamismo, pela imprevisibilidade e pela conjunção de fatores subjetivos como são a participação e a tomada de consciência. Somente visitas in loco, o que estava além desta 
pesquisa, poderiam propiciar informações mais detalhadas e refinadas sobre cada iniciativa. Portanto, a pretensão não foi realçar o detalhe, a particularidade, mas sim distinguir aspectos que se repetiram nos projetos e que permitam a definição de algum tipo de classificação para fins de enquadramento das experiências.

\subsection{A origem dos projetos}

Uma primeira questão que mereceu ser abordada envolveu a gênese dos projetos. Seriam as experiências em estudo uma transposição, com as adaptações necessárias, de iniciativas já introduzidas e testadas em outros locais ou, ao contrário, tratar-se-iam de projetos inteiramente novos, construídos unicamente a partir da própria realidade problematizada que se quer transformar e sem qualquer inspiração em ações já materializadas? As informações constantes nos projetos permitem deduzir que, na amostra, um número maior de experiências considera original sua metodologia, sem sustentação em qualquer prática anterior.

Quanto às experiências que afirmaram ter recebido influências externas, foram diversas as fontes inspiradoras mencionadas, constando desde ações locais até iniciativas de procedência internacional. Observa-se que já existe, ainda que não na intensidade ideal, um intercâmbio entre experiências municipais que ultrapassa as fronteiras regionais.

\subsection{Recursos Financeiros}

A questão financeira sempre assumiu um papel destacado no momento da implementação de projetos sociais. A escassez de recursos financeiros é, muitas vezes, a responsável direta pelo fracasso de experiências em todas as esferas da administração. É comum haver motivação e força de vontade, mas faltar as condições materiais para prosseguir com determinada atividade. Pelo exame da amostra, é possível afirmar que a questão financeira permanece sendo uma fonte de obstáculos, impedindo a consecução de muitos dos objetivos delineados.

É importante, portanto, verificar quais as características predominantes na amostra no que tange à questão do financiamento. A primeira conclusão a que se pode chegar aponta para o relevante papel assumido pelos municípios no custeio dos projetos. À exceção de algumas poucas iniciativas que não dispõem de verbas governamentais 
diretas e de algumas experiências situadas no âmbito estadual, a maioria dos projetos tem no município a sua principal fonte financiadora. Esta afirmação ganha ainda mais consistência, ao se constatar que em torno de $40 \%$ das iniciativas contam exclusivamente com recursos financeiros municipais para serem desenvolvidas. São citados exemplos de projetos totalmente dependentes das verbas locais.

a) O Programa de Enfrentamento do Risco de Escorregamento nos Morros de Santos (SP), que objetiva atenuar as conseqüências de deslizamentos de solo e rochas nos morros da cidade. Todos os gastos com pagamento de pessoal, custeio e investimento em obras e em programa habitacional são oriundos exclusivamente do orçamento municipal.

b) Programa Municipal de Transporte Escolar, em Itajá (GO), que tem como meta oferecer transporte escolar gratuito aos alunos das áreas rurais do município, contribuindo para melhorar o rendimento escolar, eliminar o êxodo rural, aumentar o intercâmbio sociocultural entre as populações rural e urbana. Da mesma forma como o exemplo anterior, $100 \%$ dos recursos advêm dos cofres municipais.

A participação das esferas estadual e federal, assim como de outras fontes de financiamento (empresariado, ONGs) ocorre numa proporção menor, porém não menos importante. Daí é possível explicitar mais uma das características da amostra, qual seja, o entrelaçamento de recursos oriundos dos diversos níveis governamentais, muitas vezes associados a financiamentos provenientes de organizações nãogovernamentais ou do próprio setor empresarial. Muitas experiências foram financiadas por recursos de duas ou mais fontes distintas. Alguns exemplos de iniciativas onde se verificou esta comunhão de fontes de recursos são citados.

a) Programa de Saúde da Família, em Campina Grande (PB), destinado a dar assistência integral às famílias beneficiadas, a mobilizar a população em torno do tema saúde e a identificar grupos de risco como hipertensos, diabéticos, desnutridos. Neste programa, o financiamento é tripartite, com os recursos sendo oriundos das esferas municipal e estadual e de uma ONG.

b) Projeto Casa Rosa Mulher, em Rio Branco (AC), voltado para o atendimento de meninas, adolescentes e mulheres em situação de risco pessoal e social. Compartilhavam, em 1995, a tarefa de financiar o projeto a Secretaria Municipal do Trabalho e Bem-Estar Social, os Ministérios da Cultura e da Saúde, o Centro 
Brasileiro para a Infância e a Adolescência -CBIA, o Instituto Brasileiro de Administração Municipal - IBAM, o Conselho Comunidade Solidária e o Fundo das Nações Unidas para a Infância - UNICEF.

Podemos concluir afirmando que as parcerias inter-governamentais e com o setor não governamental continuam sendo buscadas para a viabilização de projetos. Porém, mais significativo ainda foi constatar que o próprio poder local tem chamado para si a responsabilidade de sustentar financeiramente um número elevado de experiências, o que evita depender do repasse de recursos que encontram-se fora de seu controle (ver anexo III).

\subsection{Abrangência das questões}

A classificação dos projetos por áreas e subáreas apresentada anteriormente, apesar de ser relevante como guia dos principais temas tratados pelos projetos, é insuficiente para que tenhamos uma visão mais completa do conjunto de questões abarcadas pelas iniciativas.

Neste momento, ao invés de temas gerais, estamos interessados em verificar quais as questões sociais que dão configuração aos projetos. Baseado nas informações prestadas nos questionários respondidos pelos responsáveis pelos projetos, é possível apresentar a seguinte distribuição das principais questões sociais abrangidas e também do número de aparições de cada uma (Tab. 2).

A pluralidade de temas encerrados na amostra aponta para a diversidade das demandas sociais que se multiplicam por todo o país. Questões tradicionais como a saúde, a educação, a alimentação e a habitação mesclam-se com intervenções em áreas cuja consciência de sua importância tem aumentado nos últimos tempos: a preservação do meio ambiente, a democratização da comunicação e a valorização da cultura e do lazer. Outrossim, é patente a concentração de iniciativas destinadas a atuar no sentido de reverter situações iminentes ou já consumadas de marginalização social. 
Tabela 2 - Distribuição das Questões Sociais pelos Projetos

\begin{tabular}{|l|c|}
\hline \multicolumn{1}{|c|}{ Questões Sociais } & Números de Aparições \\
\hline Geração de emprego e renda & 33 \\
\hline Conquista de direitos & 25 \\
\hline Educação & 24 \\
\hline Saúde & 22 \\
\hline Alimentação/Abastecimento & 18 \\
\hline Meio Ambiente & 16 \\
\hline Cultura/Lazer/Esporte & 15 \\
\hline Habitação/Urbanização/Saneamento & 14 \\
\hline Comunicação/Informação & 12 \\
\hline Agricultura/Pecuária/Extrativismo & 12 \\
\hline Transporte/Trânsito & 6 \\
\hline
\end{tabular}

No que diz respeito à organização social dos beneficiários, esta preocupação insere-se de diferentes maneiras nas experiências. Em alguns poucos casos, é considerada prérequisito para a participação no projeto. Invariavelmente, porém, a organização social é vista como um dos resultados que se quer alcançar, sendo identificada, muitas vezes, como sinônimo da conquista da capacidade de autogerir a continuidade da própria experiência.

O incremento e a democratização da gestão pública também compõem o rol dos temas enfocados pela amostra. Como já foi visto em alguns projetos, a população é apenas beneficiária indireta da iniciativa, uma vez que os objetivos propostos são buscados internamente ao serviço público, atingindo, assim, o funcionalismo e as rotinas de trabalho. Inversamente, várias experiências se caracterizam por estimular o envolvimento da participação e da organização sociais em processos dedicados a promover a democratização da administração através da criação de espaços ampliados para a discussão do orçamento, a definição de prioridades, o planejamento de ações, a prestação de contas.

Um aspecto a ser abordado relaciona-se à natureza multifacetada de vários projetos. Em outras palavras, ao invés de unidimensionadas, as iniciativas, em grande número, abraçam várias demandas simultaneamente. Esta visão parece assinalar uma tendência 
à implementação de projetos que levem em consideração a organicidade dos problemas sociais, em oposição a uma visão segmentada da realidade, onde a complexidade e a interdependência das questões são ignoradas. Corroborando esta afirmação, não foi incomum divisar experiências com penetração em três ou mais situações-problema. Toda esta pluralidade fica patenteada em exemplos como os que são apresentados.

a) $\mathrm{O}$ Projeto Creche Comunitária, em Teresina (PI), que assiste as crianças provenientes de famílias indigentes, que vivem em favelas e vilas na zona periurbana, através de ações nas áreas de saúde, alimentação, educação, além de estimular o envolvimento das organizações comunitárias através da divisão das tarefas e responsabilidades concernentes ao projeto.

b) O Projeto Jaburu, em Nova Xavantina (MT), realizado junto com a comunidade xavante local. Trata-se de um projeto que associa uma preocupação fundamental, a preservação da cultura indígena, com ações pautadas na geração de renda, na educação ambiental e no fortalecimento das organizações indígenas.

c) O Projeto Meninas de Santos, em Santos (SP), que atende crianças e adolescentes do sexo feminino, vítimas da exploração sexual ou em risco de se prostituir. As atividades desenvolvidas junto a esse público compreendem áreas diversas como a educação, a saúde, o lazer, a cultura, o esporte e a geração de emprego e renda, integrando-as num esforço concentrado na tarefa de valorizá-las enquanto seres humanos, mulheres e cidadãs.

Pela análise dos resultados da amostra, nota-se que a questão da sobrevivência material ocupa um lugar de destaque. A inserção desta preocupação nos programas e projetos ocorre basicamente, de duas maneiras. A primeira, na condição de objetivo central através, por exemplo, da criação de fundos para o financiamento dos pequenos produtores rurais, micro-empresas, profissionais autônomos e cooperativas. A segunda, como mais unia entre várias ações adotadas em conjunto, para transformar a realidade de algum segmento social marginalizado. Nestas experiências de superação da pobreza material, os beneficiários manifestam graus variados de comprometimento com o processo vivenciado. A participação popular nas experiências oscila entre dois extremos: a recepção passiva de benefícios definidos de "cima para baixo" e uma 
posição ativa de envolvimento nas decisões, incluindo um esforço de organização social dos participantes, "de baixo para cima".

\subsection{Parcerias: saída para a viabilização de projetos}

A formação de parcerias envolvendo Estado e sociedade é unia característica metodológica que predomina na maioria das iniciativas examinadas. Poucas foram as experiências concretizadas sem que houvesse algum tipo de composição entre as várias esferas de governo e que não contassem com a participação de pelo menos uma das organizações a seguir: associações comunitárias, instituições religiosas ou de ensino, ONGs, sindicatos, setor empresarial e organismos internacionais (ver anexo IV). Podemos estimar em mais de $50 \%$ o número de projetos colocados em prática pela conjunção de esforços oriundos de três ou mais entidades das citadas anteriormente. A quantidade e a diversidade de formatos assumidos pela parceria entre Estado e sociedade na implementação de projetos descortinam um novo e amplo universo de possibilidades para a superação de problemas sociais, todas fundadas na aglutinação de esforços e na divisão de responsabilidades.

Um exemplo típico desta parceria é encontrado no Programa Cidade Mãe, em Salvador (BA). Seu objetivo é assistir crianças e adolescentes das comunidades de baixa renda através da implantação de Casas de Acolhimento Noturno e de Empresas Educativas, espaços destinados ao desenvolvimento de atividades de cultura, esporte e lazer e de cursos de iniciação profissional, educação para a saúde. Nesta tarefa estão associadas a Prefeitura de Salvador, o Serviço Nacional da Indústria - SENAI, a Universidade Federal da Bahia, o Centro Projeto Axé (ONG), os Conselhos Tutelares, a Organização das Nações Unidas para a Educação, Ciência e Cultura - UNESCO, o UNICEF e outras instituições.

Outra característica marcante no que tange à questão da parceria refere-se à intersetorialidade das ações, ou seja, a interação entre diversas secretarias e órgãos de governo no desenvolvimento de projetos. A articulação de políticas e a priorização de determinadas questões que passam a ser alvo do esforço concentrado da administração pública têm sido observadas em diversas experiências. Vale ressaltar que sua consecução depende de uma ação harmônica e dialógica entre os diversos organismos, o que nem sempre é uma tarefa de fácil concretização no setor público. 
O Programa Saúde da Família, de Joinville (SC), é ilustrativo do empenho intergovernamental para dar vida a uma iniciativa. Em cooperação com ONGs e organizações comunitárias, nada menos que seis secretarias municipais compartilham ações de modo a promover um atendimento integral à saúde, sobretudo às famílias com dificuldade de acesso a esse serviço.

Tanto a ampliação da interação entre Estado e sociedade quanto a integração entre órgãos públicos podem ser consideradas conquistas e inovações de primeira linha em termos de metodologias de projetos sociais. A comunhão de esforços é o caminho para superar obstáculos, sobretudo a falta de recursos. É capaz de gerar uma sinergia que ultrapassa a qualquer retorno obtido por intermédio do somatório de ações isoladas.

\subsection{Outros aspectos concernentes à metodologia dos projetos}

Um aspecto importante que pode ser extraído do conjunto das experiências estudadas relaciona-se a sua capacidade de replicação. Apesar de serem projetos localizados no espaço micro e dispersos geograficamente pelo pais, é significativa a generalidade de suas características. São experiências que podem ser transferidas para outras comunidades, dependendo apenas de adaptações periféricas, levando-se em consideração as especificidades locais.

Como já foi dito, a participação, para ser legítima e voltada para um objetivo que é a conquista da cidadania, deve abranger o envolvimento ativo do indivíduo na construção da realidade que almeja. Num processo democrático, as transformações devem ser feitas tomando como base a vontade daqueles que serão afetados pelos resultados da intervenção. Logo, o papel de definir sobre qual questão atuar e o que priorizar cabe à população, em conjunto com o poder público. Pelo material que serviu de subsídio à pesquisa, observa-se que nem sempre o ponto de partida das experiências esteve localizado na sociedade, mas sim numa decisão tomada de forma independente pelo poder público. Em função da multiplicidade de carências que precisam ser eliminadas, esta constatação não implica comprometimento do restante do processo. Todavia, a questão que se coloca é saber até que ponto a escolha feita condizia com as prioridades da comunidade atingida.

Com relação à construção das experiências, ou seja, o processo que tem início com o planejamento e prossegue com a sua implementação, acompanhamento e avaliação, 
nota-se uma grande variação de enfoques no que tange à participação. Basicamente, estes enfoques podem ser desmembrados em dois grupos: de um lado, as experiências que valorizam mais o beneficio gerado e colocado à disposição do que o processo montado para alcançá-lo. Nestes casos, a participação social ao longo do processo assume uma posição secundária. De outro, enquadram-se os projetos que tomam a participação e a organização social dos beneficiários como elementos centrais e indispensáveis na elaboração e implantação da experiência. Fugindo de um maniqueísmo simplificador, entendemos que os projetos se espalham ao longo de um continuum que é limitado de um lado pelos projetos que se assemelham a "pacotes", ou seja, são entregues prontos e acabados aos beneficiários finais, e de outro, pelos projetos voltados para a conquista da autogestão do próprio processo pelos beneficíarios e onde a participação e o grau de mobilização são os principais responsáveis pela qualidade dos resultados.

Dispostos ao longo deste continuum, os projetos apresentam conformações distintas. De um modo geral, porém, foram geridos, predominantemente, a partir de estruturas burocráticas já existentes, sem a necessidade de criação de aparatos administrativos extras.

Um comentário merece ser feito a respeito da avaliação das experiências. Em primeiro lugar, é necessário estabelecer a distinção entre dois tipos de avaliação: de processo e de produto. Basicamente, a diferenciação entre ambas está centrada no objeto a ser avaliado. $\mathrm{Na}$ avaliação do processo estão em análise não os resultados alcançados mas a estrutura montada e os instrumentos aplicados para obtê-los. Em outras palavras, está em foco a eficiência da experiência. Já a avaliação do produto visa a apreciação dos resultados em si, ou seja, tem o objetivo de medir a eficácia do projeto. Este discernimento é importante em função daquilo que foi observado na amostra: enquanto a avaliação do produto foi uma constante nas experiências, a avaliação do processo foi uma prática muito menos observada.

A avaliação dos resultados é normalmente considerada como uma necessidade de justificar, perante a sociedade, a razão da existência e a legitimidade de uma determinada ação. Consiste, basicamente, na comparação entre dois momentos distintos de uma mesma realidade: o antes e o depois da implementação do projeto. Sem entrar na discussão sobre a qualidade dos indicadores selecionados, quase todos os projetos praticam alguma forma de avaliação de resultados. A avaliação feita em 
conjunto entre o poder público e a sociedade é observada em várias experiências, sobretudo através de reuniões de avaliação. Contudo, em um contingente ainda maior de iniciativas, a avaliação ainda é feita pura e simplesmente por meio de observação, às vezes as sistemática, das alterações introduzidas, sem maior comprometimento com a participação daqueles efetivamente afetados.

Por seu turno, a avaliação do processo é muito mais delicada por constituir-se essencialmente num procedimento de autocrítica coletiva sobre comportamentos e responsabilidades assumidas que nem sempre os promotores dos projetos estão dispostos ou sabem como levar adiante. De fato, a adoção de mecanismos de avaliação de processo não foi largamente observada nos projetos. Todavia, nos casos em que se verificou a sua realização, foi significativa, para a sua concretização, a parceria entre o poder público, as demais entidades participantes e os próprios beneficiários.

Um exemplo de estrutura que abrange tanto avaliação do processo quanto dos resultados é oferecido pelo Projeto Desafio, implantado em Ipatinga (MG). Trata-se de uma experiência realizada junto aos alunos com carências afetiva, social, cognitiva e material, em escolas da periferia da cidade, no sentido de gerar um incremento no rendimento escolar associado à formação integral do indivíduo enquanto cidadão. Para avaliar a iniciativa foi montada uma tabela que pode servir de modelo para outras experiências e onde estão claramente definidos os focos de análise, os responsáveis pela avaliação, os indicadores a serem empregados e os instrumentos de coleta. Especificamente com relação à avaliação do processo, foi estabelecido o seguinte esquema:

Exemplo de Avaliação de Processo

\begin{tabular}{|c|c|c|c|}
\hline $\begin{array}{l}\text { Quem é } \\
\text { avaliado? }\end{array}$ & Quem avalia? & O que é avaliado? & Como? \\
\hline $\begin{array}{l}\text { Projeto } \\
\text { Desafio }\end{array}$ & $\begin{array}{l}\text { Alunos, pais, } \\
\text { professores, direção e } \\
\text { Coordenação }\end{array}$ & $\begin{array}{ll}> & \text { Exequibilidade; } \\
& \text { Transformação dos } \\
& \text { individuos; } \\
& \text { Qualidade do trabalho e } \\
& \text { progressão e permanência } \\
\text { do aluno; }\end{array}$ & $\begin{array}{l} \\
\begin{array}{l}\text { Reuniões bimestrais } \\
\text { com a comunidade }\end{array} \\
\text { escolar; } \\
\end{array}$ \\
\hline
\end{tabular}

Os projetos sociais, em especial os que empregam metodologias participativas, têm no processo avaliativo um aspecto ainda a ser aprimorado. Devem ser sistematizados não somente mecanismos para a avaliação final, mas instrumentos de acompanhamento da 
evolução do projeto. Esta preocupação, já identificada em diversas experiências, deve ser disseminada até o ponto de se tornar uma prática corriqueira. A avaliação permanente, entendida enquanto sinônimo de controle democrático, pautada na participação eqüitativa de todos os envolvidos, consubstancia-se no único caminho para efetuar eventuais correções ou alterações nos objetivos propostos sem significar a perda da legitimidade do processo. 


\section{Conclusões}

O conjunto de experiências examinadas pode equivaler a uma fotografia do estágio atual do desenvolvimento de projetos sociais no Brasil. A partir dos anos 90, houve uma aceleração no germinar de experiências por todo o país, aproveitando a conjuntura política favorável e tendo o nível local como seu hospedeiro-mor. Afim de driblar novos e antigos obstáculos, soluções criativas vêm sendo buscadas, sobretudo a partir da inclusão da participação e da parceria Estado-sociedade nas metodologias empregadas.

Porém, tanto os processos participativos postos em práticas, quanto as parcerias firmadas não são adotados do mesmo modo, na mesma intensidade e para o mesmo fim, se analisado cada projeto. Daí a pluralidade de configurações e também a dificuldades em se estabelecer categorias rígidas para a classificação metodológica das experiências.

O momento atual é o de consolidar as conquistas e inovações, bem como o de vencer os obstáculos e as deficiências que ainda persistem. Ambas as tarefas não são desprezíveis uma vez que os projetos estão, em sua grande maioria, circunvizinhos por e assentados sobre estruturas arcaicas de poder, interesse resistentes a transformações sociais de maior vulto e processos participativos e de organização social ainda não completamente sedimentados.Obstáculos como a falta de uma prática mais prolongada de participação social, o descrédito com relação às instituições públicas, e mais, a descontinuidade administrativa e a carência de recursos, sobretudo os de natureza financeira, são ameaças que rondam permanentemente e pairam ameaçadoras sobre o futuro dos projetos.

A superação destas ameaças requer tempo. Somente o tempo é capaz de promover uma prática participativa autêntica, uma vez que a participação é um aprendizado contínuo e seu aperfeiçoamento se dá não só pelo reconhecimento dos acertos mas também dos erros. Outrossim, a natureza da participação social, que implica abertura de canais de comunicação para a discussão de idéias e encaminhamento de ações concretas, faz com que a confiança mútua entre os participantes seja um requisito essencial para que o processo seja levado adiante. A falta de credibilidade é o caminho mais curto para o desengajamento e, consequentemente, para a interrupção de iniciativas.

O descrédito do poder público perante a sociedade dificulta a formação de parcerias entre entidades da sociedade civil e órgãos do Estado. Do ponto de vista da população, a desconfiança é fruto de uma longa história de espoliação coletiva imposta por um Estado dominado por poucos, e se reflete na descrença com relação às ações emanadas do âmbito 
estatal e desestímulo a uma participação popular mais efetiva. Para reverter esta imagem, os projetos sociais devem apresentar uma gestão democrática, por intermédio da adoção de metodologias participativas que se caracterizem pela criação de espaços para a participação plena e pelo incentivo à organização dos beneficiários para que estejam aptos a opinar, decidir e avaliar o processo, garantindo, assim, a sua legitimidade.

Cabe frisar que alguns projetos estavam comprometidos com a proposição de alguma inovação de natureza técnica muito mais do que preocupados com práticas participativas. De um modo geral, porém, as metodologias observadas na amostra adotam, parcial ou integralmente, alguma das características acima identificadas. Em relação aos projetos tradicionais, as medidas implementadas como a composição de parcerias, a democratização das informações, o apoio à autogestão, o fortalecimento das organizações comunitárias, o reconhecimento do saber popular e a abertura de canais de comunicação entre Estado e sociedade são inovações que devem ser aprimoradas.

Metaforicamente, as experiências analisadas poderiam ser comparadas a oásis de criatividade e de esperança em meio a um deserto dominado pela descrença no poder público e pela ausência de perspectivas de soluções para as questões sociais. Tendo em vista o potencial de idéias e soluções baseadas em metodologias participativas que de outra maneira permaneceriam ilhadas, sem qualquer efeito multiplicador, o Programa Gestão Pública e Cidadania pode ajudar a estreitar a troca de experiências, divulgando iniciativas que, de outra maneira, permaneceriam ignoradas, sem possibilidade de serem replicadas e aperfeiçoadas. 


\section{Anexo I}

\section{Lista das Experiências}

\begin{tabular}{|c|c|c|}
\hline $\mathbf{N}^{\mathbf{0}}$ & Nome & Local \\
\hline 1 & Administração Estratégica & Vitória-ES \\
\hline 2 & Apoio ao Pequeno Produtor & Franca-SP \\
\hline 3 & $\begin{array}{l}\text { Assistência Odontológica Integrada ao Defíciente. Mental e Portador de } \\
\text { Paralisia Mental }\end{array}$ & Araçatuba-SP \\
\hline 4 & Assistência Previdenciária & Itapeva-SP \\
\hline 5 & Campanha Seja um Anjo da Guarda & Santos-SP \\
\hline 6 & Cartão do Contribuinte Municipal - CCM & Bauru-SP \\
\hline 7 & Casa do Cidadão & Vitória-ES \\
\hline 8 & Centrais de Abastecimento de Campinas S/A & Campinas-SP \\
\hline 9 & Centro de Atendimento à Mulher - Coordenadoria Especial da Mulher & Londrina-PR \\
\hline 10 & Centro de Treinamento em Atenção Integral à Saúde da Mulher & Rio de Janeiro-RJ \\
\hline 11 & Centros de Convivência & Belo Horizonte-MG \\
\hline 12 & CEPAE & Franca-SP \\
\hline 13 & Circo da Cidade & Lages-SC \\
\hline 14 & Coleta de Sementes Nativas do Cerrado e Matas & Franca-SP \\
\hline 15 & $\begin{array}{l}\text { Comissão Permanente de Investigação e Fiscalização das Condições de } \\
\text { Trabalho }\end{array}$ & MS \\
\hline 16 & Conselho do Orçamento Participativo & Angra dos Reis-RJ \\
\hline 17 & Curso de Administração Municipal de Araraquara & Araraquara-SP \\
\hline 18 & Ecomoradia & Cuiabá-MT \\
\hline 19 & Educação Ambiental & Angra dos Reis-RJ \\
\hline 20 & Fazendo Arte com os Livros-Montagem de uma Biblioteca Infantil & Bauru-SP \\
\hline 21 & Fundagro & Vacaria-RS \\
\hline 22 & Fundo de Desenvolvimento Agropecuário do Município de Tupandi & Tupandi-RS \\
\hline 23 & Fundo de Geração de Emprego e Renda - FUNGER & Terersina-PI \\
\hline 24 & Geração de Trabalho para Adolescentes com Trajetória de Rua & Belo Horizonte-MG \\
\hline 25 & Gerenciamento Comunitário & Cuiabá-MT \\
\hline 26 & Hortas Comunitárias & Teresina-PI \\
\hline 27 & Implantação de Escolas Indígenas - Minas Gerais & Reservas Indígenas-MG \\
\hline 28 & Jovem Cidadão Consciente e Participante em sua Comunidade & São Vicente-SP \\
\hline 29 & Jusagilizar & Estado do Rio Grande do Sul \\
\hline 30 & Justiça Tributária & Governador Valadares-MG \\
\hline 31 & Microurbanização Integrada do Castelinho & Fortaleza-CE \\
\hline 32 & Modelo de Gestão de Resíduos Sólidos & Belo Horizonte-MG \\
\hline 33 & Municipalização e Participação Popular & Diadema-SP \\
\hline 34 & Museu Maguita & Benjamin Constant-AM \\
\hline 35 & Mutirão em Autogestão & Ipatinga-MG \\
\hline 36 & $\begin{array}{l}\text { Novos Modelos de Gestão do Estado - Descentralização e Força dos } \\
\text { Municípios }\end{array}$ & Várias Cidades-RO \\
\hline 37 & Núcleo de Informação em Mortalidade & Londrina-PR \\
\hline 38 & O Projeto Conviver em Duque Bacelar & Duque Bacelar-MA \\
\hline 39 & Obras em Parceria com a Comunidade & Salvador-BA \\
\hline 40 & Orçamento Participativo & Ipatinga-MG \\
\hline 41 & Ouvidoria Pública Municipal & Santos-SP \\
\hline 42 & Plano de Revitalização da Bacia da Lagoa Olho D’Água & Jaboatão dos Guararapes-PE \\
\hline 43 & Plano Preventivo de Defesa Civil - PPDC & $\begin{array}{l}\text { Baixada Santista e Litoral } \\
\text { Norte-SP }\end{array}$ \\
\hline 44 & $\begin{array}{l}\text { Pol. Urbana em Diadema/Urbaniz. De Favelas como Proc. De Constr. Da } \\
\text { Cidadania }\end{array}$ & Diadema-SP \\
\hline 45 & Polícia Interativa & Guacuí-ES \\
\hline 46 & Pólo Agroflorestal & Rio Branco-AC \\
\hline
\end{tabular}




\begin{tabular}{|c|c|c|}
\hline 47 & Porto Alegre Mais-Cidade Constituinte & Porto Alegre-RS \\
\hline 48 & Programa Bolsa Familiar para Educação/Bolsa Escola & Distrito Federal \\
\hline 49 & Programa Brincando na Rua & Porto Alegre-RS \\
\hline 50 & Programa Câmbio Verde & Curitiba-PR \\
\hline 51 & Programa Cidadão Criança & Vitória-ES \\
\hline 52 & Programa Cidade Mãe & Salvador-BA \\
\hline 53 & Programa de Atendimento à Criança e ao Adolescente & Canoinhas-SC \\
\hline 54 & Programa de Democratização de Informações & Belo Horizonte-MG \\
\hline 55 & Programa de Enfrentamento do Risco de Escorregamento nos Morros & Santos-SP \\
\hline 56 & Programa de Garantia de Renda Familiar Mínima & Campinas-SP \\
\hline 57 & Programa de Geração de Emprego e Renda & Quixadá-CE \\
\hline 58 & Programa de Humanização do Trânsito & Novo Hamburgo-RS \\
\hline 59 & Programa de Microbacias Hidrográficas-Projeto PEGA OO POTI & $\begin{array}{lll}\text { Aldeia Guarani } & - & \text { São } \\
\text { Sebastião-SP } & & \\
\text { Sa }\end{array}$ \\
\hline 60 & Programa de Ocupação Gerenciada & Ituiutaba-MG \\
\hline 61 & Programa de Saúde da Família & Campina Grande-PB \\
\hline 62 & Programa de Saúde do Trabalhador Rural de Fagundes & Fagundes-PB \\
\hline 63 & Programa Hortas Comunitárias & Birigui-SP \\
\hline 64 & Programa Intersecretarial de Atendimento à Terceira Idade & São Paulo-SP \\
\hline 65 & Programa Médico da Família & Londrina-PR \\
\hline 66 & $\begin{array}{l}\text { Programa Munic. De Atuação na Cadeia Agroalimentar do Leite - PRÓ } \\
\text { LEITE }\end{array}$ & Juiz de Fora-MG \\
\hline 67 & Programa Municipal de Informação ao Consumidor & Juiz de Fora-MG \\
\hline 68 & Programa Municipal de Transporte Escolar & Itajá-GO \\
\hline 69 & Programa Nutrir & Apucarana-PR \\
\hline 70 & Programa Pobreza e Meio Ambiente na Amazônia & Vários Estados do Brasil \\
\hline 71 & Programa Saúde da Família & Joinville-SC \\
\hline 72 & Programa Saúde Global & Joaíma-MG \\
\hline 73 & Programa SOS Tr6Ansito - Um Projeto de Vida & Estado de Minas Gerais \\
\hline 74 & Projeto Casa Rosa Mulher & Rio Branco-AC \\
\hline 75 & Projeto Casulo & São José dos Campos-SP \\
\hline 76 & Projeto Creche Comunitária & Teresina-PI \\
\hline 77 & $\begin{array}{l}\text { Projeto de Criação e Implantação de Postos de Serviços e Atendimento ao } \\
\text { Cidadão }\end{array}$ & Salvador-BA \\
\hline 78 & Projeto de Geração de Trabalho e Renda & Betim-MG \\
\hline 79 & Projeto Desafio & Ipatinga-MG \\
\hline 80 & Projeto ICMS Ecológico & Estado do Paraná \\
\hline 81 & Projeto Jaburu & Nova Xavantina \\
\hline 82 & Projeto Meninas de Santos & Santos-SP \\
\hline 83 & Projeto Menino no Parque & Belo Horizonte-MG \\
\hline 84 & Projeto São Pedro - Desenv. Urbano Integrado e Preserv. Do Manguezal & Vitória-ES \\
\hline 85 & Projeto Terra Solidária & Iguaraçu-PR \\
\hline 86 & Rádio Muleke & Santos-SP \\
\hline 87 & República Reviver & Belo Horizonte-MG \\
\hline 88 & Seminários Legislativos & Estado de Minas Gerais \\
\hline 89 & Serviço 156 & São José dos Campos-SP \\
\hline 90 & Serviço de Atendimento Domiciliar - SAD & Campinas-SP \\
\hline 91 & Sistema Curitiba de Coleta e Tratamento de Esgoto Sanitário & Curitiba-PR \\
\hline 92 & Sistema de Acompanhamento Orçamentário & Angra dos Reis-RJ \\
\hline 93 & Sistema Integrado da Cidadania - SISDANIA & Estado do Paraná \\
\hline 94 & Trabalhando com Mutirões - Grupo Procurando Soluções & Caxias do Sul-RS \\
\hline 95 & Trânsito - Cidadania e Responsabilidade & $\begin{array}{l}\text { Estado do Mato Grosso do } \\
\text { Sul }\end{array}$ \\
\hline 96 & TV Pública Municipal & Itabira-MG \\
\hline 97 & Um Canto em Cada Canto & Fortaleza-CE \\
\hline 98 & Um novo Modelo de Gestão & Estado de Rondônia \\
\hline 99 & Unidade Experimental de Compostagem e Reciclagem & Brazlândia-DF \\
\hline 100 & Universalização do Ensino em Icapuí & Icapuí-CE \\
\hline
\end{tabular}




\section{Anexo II}

\section{Distribuição da Amostra por Áreas e Sub-Áreas}

\begin{tabular}{|c|c|}
\hline Área 1: Administração e Governo & 22 \\
\hline Formas de Gestão e Planejamento & 8 \\
\hline Orçamento Público & 1 \\
\hline Finanças Públicas & 2 \\
\hline Sistemas de Informação & 3 \\
\hline Participação Popular & 6 \\
\hline Recursos Humanos e Relações de Trabalho & 2 \\
\hline Área 2: Infra-Estrutura e Meio Ambiente & 12 \\
\hline Infra-Estrutura e Meio Ambiente & 2 \\
\hline Saneamento (água e esgoto) & 1 \\
\hline Trânsito e Vias Públicas & 2 \\
\hline Desenvolvimento Sustentável & 5 \\
\hline Destinação Final e Tratamento de Lixo & 1 \\
\hline $\begin{array}{l}\text { Preservação de Ecossistemas e } \\
\text { Reflorestamento }\end{array}$ & 1 \\
\hline Área 3: Serviços Públicos & 32 \\
\hline Educação & 8 \\
\hline Saúde & 9 \\
\hline Habitação & 5 \\
\hline Cultura, Lazer e Esporte & 3 \\
\hline Segurança Pública & 2 \\
\hline Assistência Social & 4 \\
\hline Previdência Social & 1 \\
\hline Área 4: Cidadania e Direitos Humanos & 20 \\
\hline Cidadania e Direitos Humanos & 3 \\
\hline Criança e Adolescente & 8 \\
\hline Idoso & 2 \\
\hline Mulher & 2 \\
\hline Deficiente & 1 \\
\hline
\end{tabular}




\begin{tabular}{|l|c|}
\hline $\begin{array}{l}\text { Consumidor } \\
\text { Minorias } \\
\text { Social }\end{array}$ & 1 \\
\hline $\begin{array}{c}\text { Área 5: Desenvolvimento Econômico e } \\
\text { Agropecuária }\end{array}$ & $\mathbf{1 2}$ \\
\hline Desenvolvimento Regional e Local & 5 \\
\hline $\begin{array}{c}\text { Geração de Empregos e Treinamento para o } \\
\text { Trabalho }\end{array}$ & 5 \\
\hline Reforma Agrária & 1 \\
\hline Área 6: Legislativo & $\mathbf{1}$ \\
\hline \multicolumn{1}{|c|}{ TOTAdiciário } & $\mathbf{1}$ \\
\hline
\end{tabular}




\section{Anexo III}

\section{Fontes dos Recursos Financeiros}

\begin{tabular}{|l|c|}
\hline \multicolumn{1}{|c|}{ Fonte } & No de Aparições na Amostra $^{\mathbf{1}}$ \\
\hline Setor Público Municipal & 73 \\
\hline Setor Público Estadual & 22 \\
\hline Setor Público Federal & 28 \\
\hline Outras* & 26 \\
\hline
\end{tabular}

*Outras: Empresas, ONGs, Organismos Internacionais etc. 
Anexo IV

Organizações Participantes

\begin{tabular}{|l|c|}
\hline \multicolumn{1}{|c|}{ Tipo de Organização } & No de Aparições na Amostra $^{\mathbf{1}}$ \\
\hline Órgãos Municipais & 88 \\
\hline Órgãos Estaduais & 34 \\
\hline Órgãos Federais & 26 \\
\hline Organizações Comunitárias & 34 \\
\hline ONGs & 28 \\
\hline Instituições Religiosas & 19 \\
\hline Instituições de Ensino & 32 \\
\hline Empresas & 21 \\
\hline Sindicatos & 13 \\
\hline Organismos Internacionais & 11 \\
\hline
\end{tabular}

